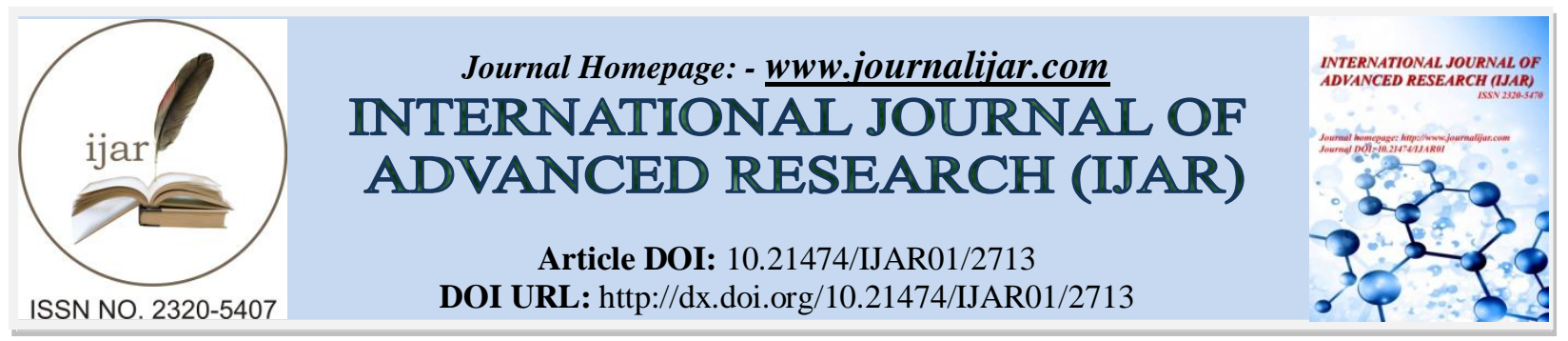

RESEARCH ARTICLE

\title{
BIOLOGICAL CONTROL OF SOIL BORNE PATHOGENS (FUSARIUM OXYSPORUM F.SP. CUCUMERINUM.) OF CUCUMBER (CUCUMIS SATIVUS) BY TRICHODERMA SP.
}

Madhu Prakash Srivastava.

Center of Excellence, Department of Botany, University of Lucknow, Lucknow-226 007. India

\section{Manuscript Info}

\section{Manuscript History}

Received: 15 November 2016

Final Accepted: 17 December 2016

Published: January 2017

Key words:-

Cucumber, Biological Control,

Fusarium oxysporum f.sp.

Cucumerinum, Trichoderma sp.

\section{Abstract}

Cucumis sativus (Cucumber) is very valuable crop plant in India. Direct application of Trichoderma $\mathrm{sp}$.has proved effective in controlling the infection by Fusarium (soil borne pathogen) one of cucumber plants under greenhouse conditions. A wilt caused by Fusarium oxysporum f.sp. Cucumerinum is a majer problem in the production of Cucumis sativus (Cucumber) plants. In dual culture a significant reduction was observed. Positive correlation between added Trichoderma and percentage of healthy cucumber seedlings were detected. Improved seedling vigour was noticed in fungal antagonist filtrate treated seeds evidenced by maximum shoot length $(19.5 \mathrm{~cm}$ respectively) followed by fungal antagonist suspension treated pot $(20 \mathrm{~cm})$ while untreated seeds in inoculated control (respectively). Percent seedling mortality was recovered in untreated seeds in uninoculated soil was $40 \%$, in coated seeds in inoculated soil was $6.25 \%$, in filtrate treated seeds in inoculated soil was $12.5 \%$ and untreated seeds in inoculated soil was $87 \%$.Percent disease control was calculated to be $86.99 \%$ for antagonist filtrate treated seeds in infected soil and $93.62 \%$ for antagonist coated seeds in infected soil over untreated seeds in Fusarium infested soil taken as check so the strongly suggest that Trichoderma $\mathrm{sp}$ can ve exploited for the biological control of soil borne pathogens ( Fusarium oxysporum f.sp. Cucumerinum.).

Copy Right, IJAR, 2016,. All rights reserved.

\section{Introduction:-}

Plant pathogens are estimated to cause yield reductions of almost $20 \%$ in the principal food and cash crops worldwide. Losses may be more severe when highly susceptible varieties are widely grown. Although these losses may be attenuated by the use of disease tolerant cultivars, crop rotation or sanitation practices. Fungicides are often essential to maximize crop yields. The predicted growth of world population from 5.7 billion in 1993 to approximately 8 billion by 2020 presents a major global challenge to meet the necessary increases in food production. Significant yield improvements are potentially achievable in staple food crops such as cereals, rice and maize through optimizing inputs, including fungicides. Fungicides also provide substantial benefits on good quality, which is related to the reduction of mycotoxins and phytotoxins.

Despite the many advantage conferred by fungicides, increasing public concern about environmental health is proving to be major hindrance in the use of the chemical pesticides including fungicides. Their indiscriminate use 
has led to several environmental problems including development of resistance in insects to insecticides, resurgence of non target, pests, and pesticides residues in food, fodder and feed, destruction of beneficial insects like honey bee, pollinators, parasites and predators. Persistent residues of Dichlorodiphenyltrichloethane and Benzene hexachloride have been detected in vegetables, milk, oil, butter, meat and even in mother's breast milk. Besides impairment of ecosystem the modern chemical input based agricultural technology has also led to poor economic returns. Some of the pathogens and pests of crop have also developed bio-types or strains or races complicating their management with the available tactics. It is therefore, quite essential to continuously monitor the changing scenario of pest, disease and weeds complexes in various cropping systems across the country and also monitors their natural enemies, which keep them under check.

The consumption of technical grade pesticides on crop has gone up from over 7341 MT in 1960 to 80,000 MT in 1989-90. It has further risen beyond 100000 MT during the year 1994-95.The estimated annual growth rate of consumption of pesticide was about $10 \%$ in the last decade. More than $60 \%$ of the pesticides are consumed in the agriculture sector. Cotton, rice and vegetables consume maximum quantity of pesticide in the country. .In case of millets, oil seeds, and pulses pesticide share is only 6-7\%. The use of pesticide is also heavy in fruits, vegetables and plantation crops but very moderate in sugarcane. Among the chemicals pesticides, insecticides are used to a large extent of about $80 \%$ in India followed by fungicides $10 \%$, herbicides $7 \%$ and other chemicals $3 \%$. The level of pesticide residue is very high in India.

The problem of pesticide residue is due to use of recalcitrant pesticides and is particularly serious in case of cereals, pulses, milk, fruit, vegetable etc. It has also affected our export of tea, coffee, rubber, fruits etc.

Ideally a chemical compound should not only be safe to the human beings and other mammals, but also to the harmless resident microflora. It should cause minimum change in microbial balance of the environment. Such concerns have led to the development of novel crop protection chemicals with low use rates, a benign environmental profile and low toxicity to human and wildlife. Use of chemical fungicides has proven hazardous to air, water and soil.

Biocontrol agents are being used as an alternate strategy to chemical pesticides as they are target specific, environment friendly due to higher selectively and biodegradable nature. For the last few decades, biological control of plant pathogens has been becoming very much popular. Some research workers from different parts of the world have tried to control fungal pathogens by applying other antagonistic microorganisms such as fungi and bacteria. Biocontrol agents form a component of integrated disease management system and can easily be integrated with other effective practices. Biocontrol agents are known as antagonists. The most important well studied antagonists against several plant pathogens are fungi like Aspergillus sp. (particularly Aspergillus niger and Aspergillus terreus), Chaetomium globosum, Coniothyrium maintains, Fusarium sp., Gliocladium virens, Penicillium citrinum, Trichoderma sp., particularly Trichoderma harzianum and Trichoderma viride and Sporodesmium sp. and bacteria like Agrobacterium radiobacter strain K84, species of Bacillus, Enterobacter, Micromonospora, Pseudomonas and Streptomyces. Microbial antagonists extensively used for soil- borne disease are species of Trichoderma, Gliocladium virens, Coniothyrium maintains, Bacillus, Pseudomonas and Streptomyces.

The study was conducted to evaluate the antagonistic property of Trichoderma sp. isolated from rhizosphere of peepal soil and its efficacy as seed coating in preventing seedling wilt.

\section{Materials and Methods:-}

\section{Isolation:-}

The fungus Fusarium sp. was isolated from infected cucumber (Cucumis sativus) fruit and fungus Trichoderma sp. was isolated from soil. Pure culture was obtained by repeated inoculation in fresh PDA medium. For it fungus mycelium was picked by help of red hot sterilized platinum -nickel alloy wire loop and transferred to the PDA plate under laminar flow. Fungus was allowed to grow for 7 to 8 days and then microscopically examined. Further by hyphal tip method pure culture plates were prepared.

\section{Soil Sampling:-}

Soil sample was collected from the rhizosphere of peepal tree located in the garden of old Botany Department' of Lucknow University. The sample was drawn, demarcated into uniform portion. For soil sample collection 20x30x 20 cubic $\mathrm{cm}$ pits were dug with sterilized spatula. Upper most $1 \mathrm{~cm}$ soil surface was scrapped off and soil surface from 
all the sides of the pit in profil was collected in sterilized polythene bag. This sample was sealed to maintain their original moisture.

\section{Isolation of Soil Mycoflora:-}

$100 \mathrm{mg}$ of peepal soil was taken in autoclaved eppendorf tube and $1000 \mu \mathrm{l}$ of distilled water was added to it to make stock solution and shake it well and other autoclaved eppendorf tubes were taken and labeled according to concentration $10^{-1}, 10^{-2}, 10^{-3}, 10^{-4}, 10^{-5}, 10^{-6} .900 \mu \mathrm{l}$ of distil water was added to each. Now $100 \mu 1$ of stock solution was added to the eppendorf tube of concentration $10^{-1}$ and shake it well. $100 \mu \mathrm{l}$ of solution from concentration $10^{-1}$-was transferred to the eppendorf tube labeled $10^{-2}$ concentration so as to make its solution $1000 \mu 1$. Now $100 \mu 1$ of solution from $10^{-2}$ concentration transferred to $10^{-3}$ labelled eppendorf tube and shake it well. Similarly $100 \mu \mathrm{l}$ was transferred from $10^{-3}$ concentration was discarded out. Plate 100 $\mu 1$ of aliquots on PDA (Potato Dextrose Agar) plates from concentration $10^{-2}, 10^{-4}, 10^{-6}$ with the help of micropipette and spread it with spreader. Plates were incubated at $27 \pm^{\circ} \mathrm{C}$ for $24 \mathrm{hr}$. in the dark. There were three replicates for each concentration. The colonies were enumerated after 7 days of incubation. The fungi were isolated as pure cultures on PDA. Fungi were exarlined for colony characteristics and microscopically for morphological studies.

\section{Bio-efficacy of Trichoderma sp in-vitro by Dual cultures:-}

Bio-efficacy of Trichoderma sp. against Fusarium oxysporum was tested under in-vitro conditions by dual culture technique. Cultures were grown on PDA in Petri plates and incubated at $27 \pm 2{ }^{\circ} \mathrm{C}$ for 7 days in three replications. The colony diameter of test fungus in dual culture with each isolate of $C$. globosum was measured and growth inhibition was expressed as a percentage of the control. In the corresponding control an equal amount of PDA was added. Day by Day we examine the radial growth of test fungi.

Antimicrobial activity was expressed in term of percentage of mycelia growth inhibition \& calculated as per formula.

In Petri plate, Percentage of mycelia growth inhibition=dc-dt $\times 100 / \mathrm{dc}$

Where

$\mathrm{dc}=$ Average Diameter of fungal colony in control

$\mathrm{dt}=$ Average Diameter of fungal colony in treatment

\section{Pot experiments:-}

\section{Soil Preparation:-}

The culture inoculum of Fusarium sp-growing on broth was mixed in the potted sterilised soil at the rate of $1 \mathrm{gm}$ per $\mathrm{kg}$. soil. Cucumber plants seeds (3 leaf stage) were shown in each pot two days after infestation with inocula of the antagonist.

\section{Preparation of inoculums:-}

Pathogen was multiplied on Potato Dextrose broth medium for 15 days at $27 \pm^{\circ} \mathrm{C}$. A $5 \mathrm{~mm}$ diameter disc of pathogen was put into the broth medium.

\section{Preparation of Antagonist:-}

For antagonist preparation antagonist was multiplied on PDA plates for 6 days and in the broth medium (PDB) for 15 days at $27 \pm^{\circ} \mathrm{C}$

\section{Coating of Seeds:-}

For seed coating the antagonist was multiplied on PDA and PDB medium for 15 days under alternate light (12 hrs.) and dark (12 hrs.) conditions. Spore suspension of the antagonist was prepared in sterile distilled water with $.01 \%$ Tween 80 , to give spore count of $10^{6}$ spores per $\mathrm{ml}$. This $100 \mathrm{ml}$ of suspension was used to coat about $5 \mathrm{gm}$ of seeds. $5 \mathrm{gm}$ of seeds were dipped in filtrate of fungal, antagonist broth culture for about 20 minutes. Seeds were dried overnight before sowing. A pot experiment was designed to find out the efficacy of antagonist in the control of 'wilting' disease of cucumber caused by Fusarium sp. Untreated cucumber seeds were sown at the rate of eight seeds per pot in sterilised soil. In second set, the biocontrol agent coated seeds were sown in pathogen mixed soil. In third set, the biocontrol agent filtrate treated seeds were sown in pathogenic soil; while in the fourth set untreated seeds were sown in pathogen inoculated Soil. There were three replicates for each set. 
The pots were kept in wire house and after seven days and fifteen days the seedlings were observed for percent germination, seedling vigour and percent disease control. (Kharakrang et. al., 2002)

$$
\mathrm{Ds} \%=\frac{\mathrm{Cm} \%-\mathrm{Tm} \%}{\mathrm{Cm} \%}
$$

Where,

Ds $\%=\%$ Disease Control

$\mathrm{Cm} \%=\%$ mortality in control

$\mathrm{Tm} \%=\%$ mortality in treated seeds in inoculated soil

\section{Result:-}

Soil sample collected from Department of Botany, Lucknow University contained higher fungal population $(\mathrm{CFU} / \mathrm{ml})$ in $10^{-2}$ concentration $\left(1.75 \times 10^{7} \mathrm{CFU} / \mathrm{ml}\right)$ followed by $10^{-4}$ concentration $\left(5.25 \times 10^{5} \mathrm{CFU} / \mathrm{ml}\right)$ followed by $10^{-6}$ concentration $\left(7.75 \times 10^{3} \mathrm{CFU} / \mathrm{ml}\right)$. Several genera had been isolated from soil including Aspergillus $s p$., Cladosporium sp., Fusarium sp., Penicillium sp., Rhizopus sp., Trichoderma sp., which were most frequent.

Table 1:- Antagonism between Trichoderma sp. (T-I) and Fusarium sp. in the dual culture test.

\begin{tabular}{|l|l|l|l|l|}
\hline \multirow{2}{*}{ Day } & Control diameter $(\mathrm{mm})$ & Dual Diameter (mm) \\
\cline { 2 - 5 } & Fusarium & Trichoderma & Fusarium & Trichoderma \\
\hline $3^{\text {rd }}$ & 32 & 28 & 32 & 28 \\
\hline $4^{\text {th }}$ & 43 & 42 & 42 & 42 \\
\hline $5^{\text {th }}$ & 57 & 42 & 47 & 43 \\
\hline $6^{\text {th }}$ & 57 & 47 & 47 & 46 \\
\hline $7^{\text {th }}$ & 57 & 54 & 48 & 50 \\
\hline $8^{\text {th }}$ & 57 & 57 & 48 & 52 \\
\hline
\end{tabular}

Graph. a,b,c,d,: Effect of seed treatment with antagonist Trichoderma sp. on seedling vigour and percent disease control of Fusarium sp. induced wilting disease of Cucumber.

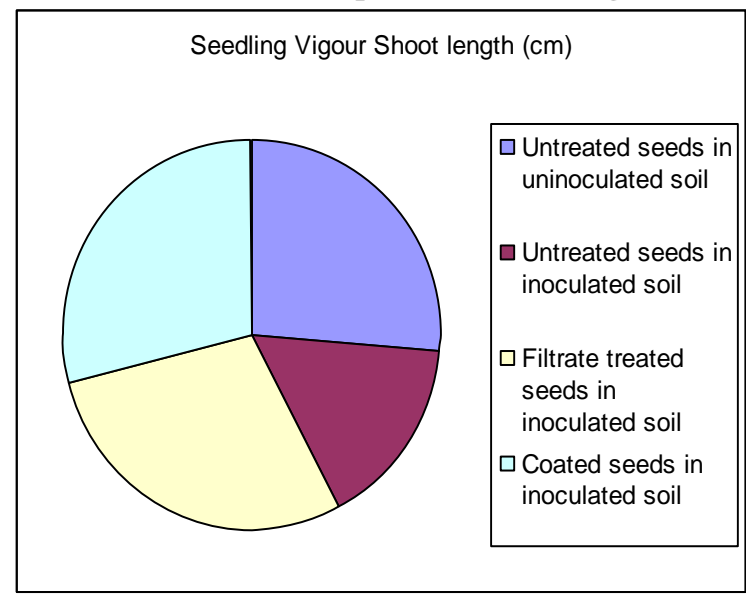

A

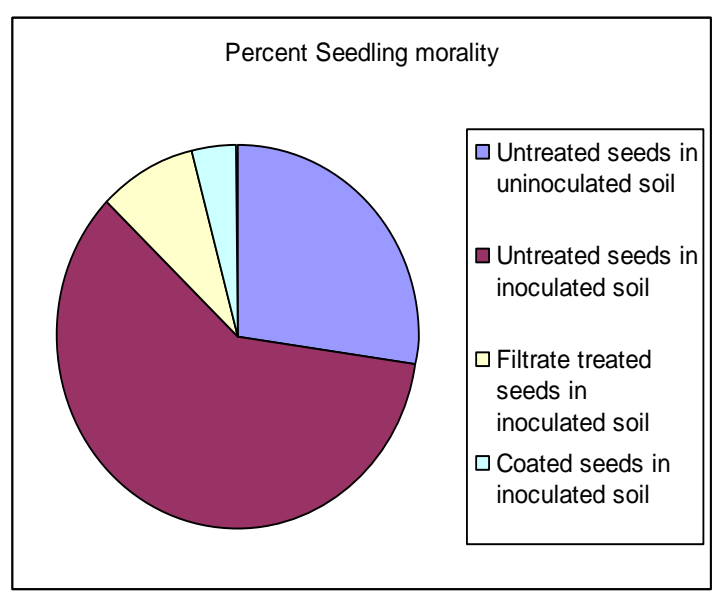

B 


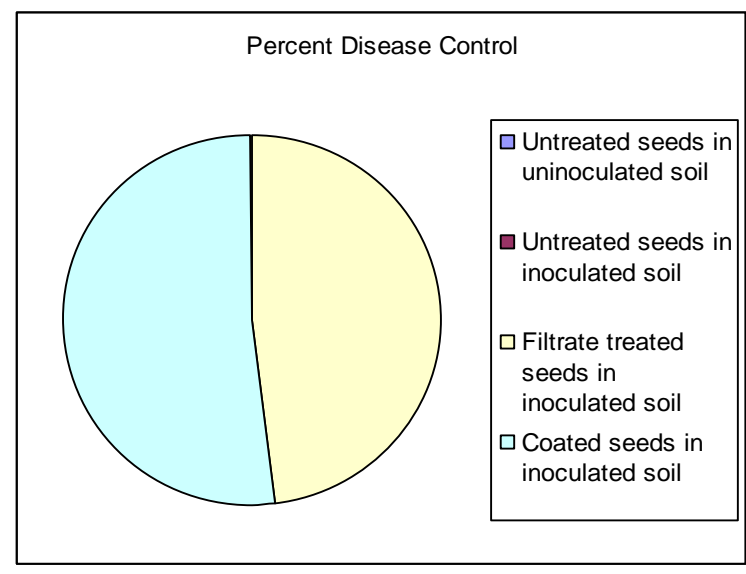

$\mathrm{C}$

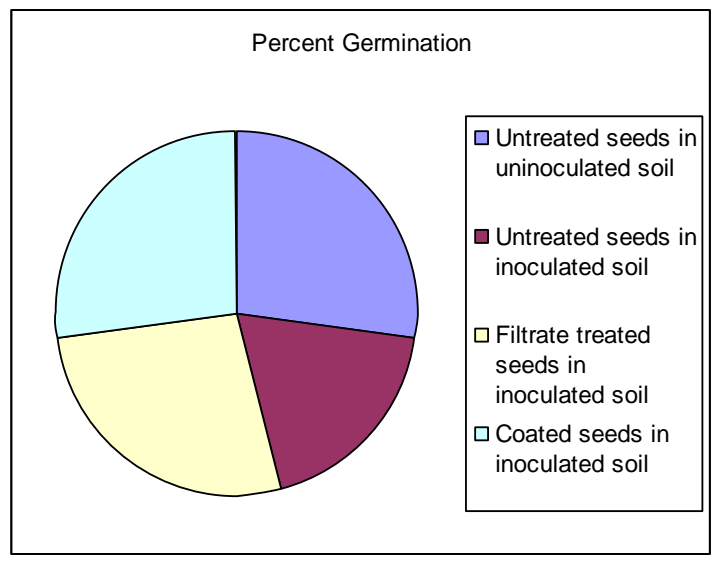

$\mathrm{D}$

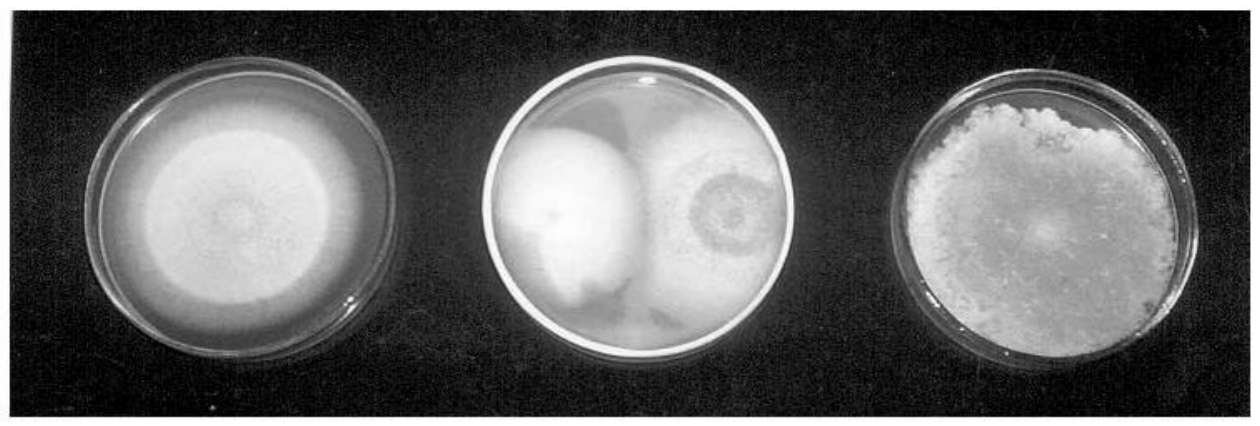

Fig 1:- a. In dual culture interaction between Trichoderma sp. and Fusarium sp.

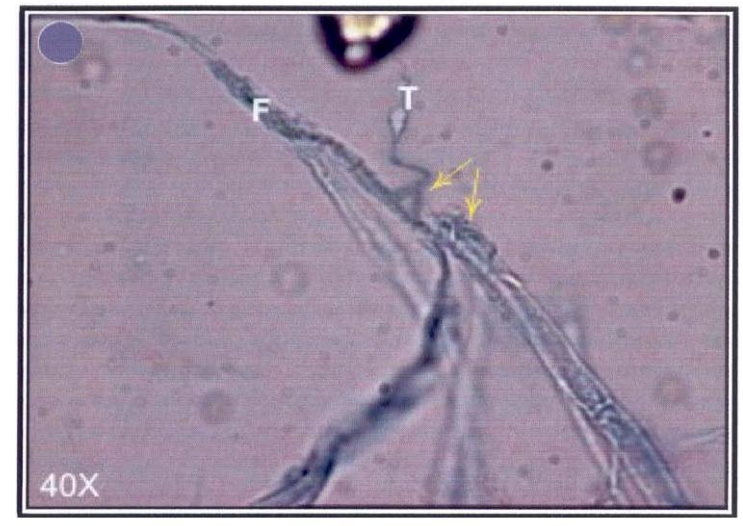

Fig 1b:- Directional growth of Hyphal branches of Trichoderma sp. towards hyphae of and Fusarium oxysporum and coiling of Trichoderma sp around that host hyphae. 


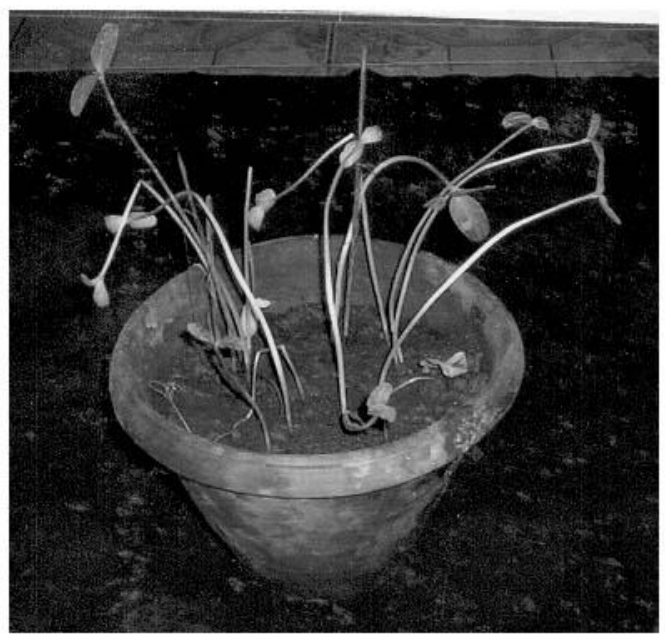

Fig 2a:- Emergent seedling from untreated seed of cucumber in non- pathogenic soil.

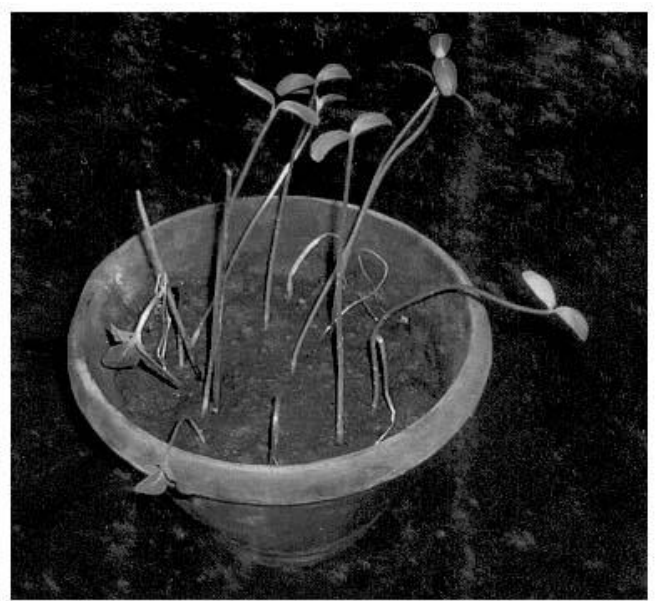

Fig 2b:- Emergent seedling from filtrate treated seed of cucumber in pathogenic soil T1.

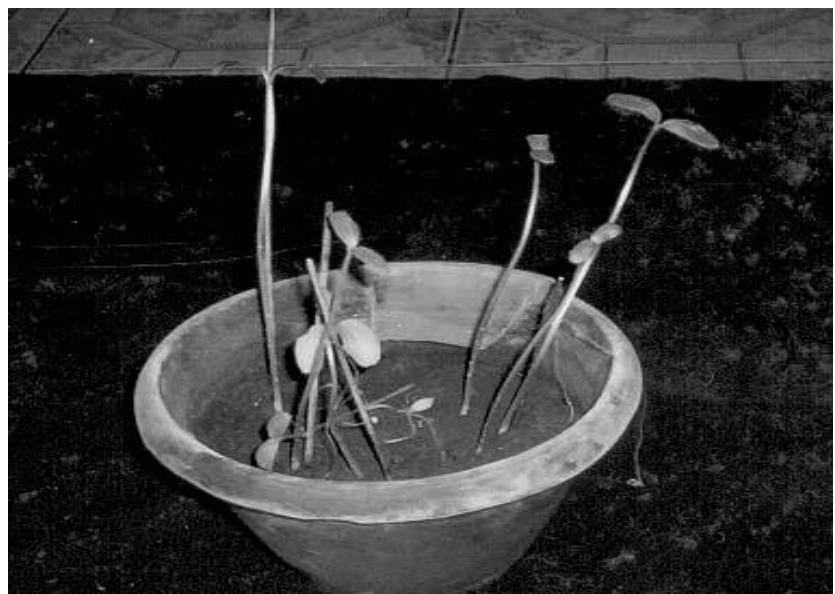

Fig 2c:- Emergent seedling from suspension coated seed of cucumber in pathogenic soil T2. 


\section{Description:-}

Identification of taxa was done after consulting the literature (Gilman, 1998). The taxa have been classified to genetic level in accordance to the classification of C.J. Alexopoulous and C. W.Mimus.

\section{Aspergillus Flavous:-}

Colonies lime-green to mignonette green widely spreading. Conidiophores arise separately from the substratum, 400- $7001000 \mu$ long x $5.15 \mu$ in diameter, broadening upward, walls so pitied as to appear rough or spiny with low magnification, occasionally granular, gradually enlarging upward to form a vesicle $10-30 \mu$ or $40 \mu$ in diameter. Heads in every colony vary from small with a few chains of conidia to large columnar masses or both mixed in same area; small heads with small dome like vesicles and single series of few phialides upto 10-15 x 3-5 $\mu$ large head partly with simple phialides and partly with branched or double series or with both in the same head; primary phialides, 7-10x3-4 $\mu$. Secondary 7- 10x2.5 -3.5 $\mu$.conidia pyriform to almost globose, colourless to yellow -green sometimes. almost smooth, usually rough varying from $2 \times 3 \mu, 3 \times 4 \mu, 4 \times 5 \mu$ or $5 \times 6 \mu$ in diameter, or even larger. Sclerotia at first white, then brown hard, paren-chymatous. Clistothecia not found.

\section{Aspergillus Niger:-}

Colonies black with streaks surrounded by white. From blue yellow coloured and shrinkage of agar medium occurs. Colonies on medium rapidly growing with abundant submerged mycelium. Conidiophores mostly arise directly from the substratum, smooth septate or non septate, varying greatly in length and diameter, 200-400 x 7-10 $\mu$ or several millimeters long and $20 \mu$ in diameter. conidial heads fuscous, blackish -brown, purple brown, in every shade to carbonous black, varying from small, almost columnar mass of few conidial chains to the more common globose or radiate heads, upto $300-500$, or $1000 \mu$ or long; vesicles globose commonly $20-5 \mu$ up to $40 \mu$ in diameter, phialides typically in 2 series thickly covering the vesicles primary varying greatly in length, secondary 6 $10 \times 2-3 \mu$. Conidia globose, at first smooth,but laterspinulose with colouring substances, mostly $2.5-4 \mu$ less frequently $5 \mu$.

\section{Cladosporium Sp:-}

Colonies on agar medium appeared greenish-black, large, thick, conidiophores at first erect, then falling, pale-green, conidia two to three celled, olive-green, 10-22m long x 4-6m thick.

\section{Fusarium Sp:-}

Colonies brownish -white to voilet appearance. The lower of the stroma plectenchymatic, chlamydospores intercalary Sporodochia lacking. Conidia scattered on aerial mycelium, spindle or sickle shaped, straight or slightly curved, not pedicellate but often with attachment water on the base. Smaller conidia 0 to 2 septate, larger 3 septate seldom 4-5 septate.

\section{Penicillium sp:-}

The mycelium is profusely branched with septate hyphae. The cells are thin walled, one to multinucleate. It has smooth walled conidiophore stipes bearing divergent whorls of metulase usually without further branches. Conidia globose to sub-globose, smooth walled not exceeding $3 \mu \mathrm{m}$ diameter. Colonies grow restrictly reaching $2.0-2.5 \mathrm{~cm}$ diameter in $10-14$ days at $27 \pm^{\circ} \mathrm{C}$.

\section{Rhizopus sp :-}

Colony appears light greyish in colour, the mycelium produces rhizoids formed specially at points where it contacts a hard surface sporangiophores erect it bears columella at upper side. After dehicing it releases zygospores. Zygospores spherical 95-250 $\mu \mathrm{m}$ in diameter.

\section{Trichoderma sp:-}

Conidia -oblong to elliposoide, dull green, 3-4.5 x $2.1-2.8 \mu \mathrm{m}$ Conidiophore -5-10 $\mu$ m diameter near the base, highly branched, primarily branches, relatively short, usually in whorls of $2-5$, highly rebranched, ultimate branch one celled, barrel- shaped or short cylindrical, mostly 3.5-7 x 3.5 $\mu$. Phialides -Sub globose to ellipsoidal or ampulliform, $3.3-5.6 \times 2.8-3.5 \mu \mathrm{m}$ arise in crowded whorls of 3-6. Chlamydospores -abundant, $33 \times 18 \mu \mathrm{m}$. Colony characters -Colonies grow moderately rapidly; limited aerial mycelium is floccose, white to grayish. 


\section{Effect of antagonists on growth of Fusarium sp by dual culture method:-}

Trichoderma sp. T1 isolated from soil exhibited antagonistic activity chiefly through hyperparasitism on Fusarium spp. (Plate-3). In the dual culture Trichoderma sp. first grew slowly towards the Fusarium sp. then grew rapidly and overgrown the colony of Fusarium in a span of fifteen days. Interaction region of 20 days old dual culture showed that hyphae of Trichoderma sp frequently encircled Fusarium hyphae.(Table 1,Fig 1 a.)

\section{In vitro interaction between Trichoderma sp. and Fusarium sp:-}

Initial examination of the extent of fungal growth in dual culture revealed that the first apparent contact between hyphae of both fungi occurred 6 days after inoculation (Table-I). Interaction region of fifteen days old dual culture exhibited hyphal interactions between Trichoderma sp. and Fusarium sp. as seen under light microscope at 40X, Trichoderma sp. coiled around the host hyphae. The coiling was either loose or massive and the host hyphae became lysed and disintegrated. (Fig. 1b)

\section{Effect of Trichoderma sp. on plants grown in pot culture:-}

Results recorded for antagonistic effects of Trichoderma sp. to the soil borne pathogen, Fusarium sp. on cucumber plants revealed that the tested pathogenic fungi was effectively controlled by the antagonists. Percent Germination of plants was highly effective when Trichoderma coated seed swoen in soil. (Fig2, Graph D).

\section{Effect on Seedling Vigour:-}

Improved seedling vigour was noticed in fungal antagonist filtrate treated seeds evidenced by maximum shoot length ( $19.5 \mathrm{~cm}$ respectively) followed by fungal antagonist suspension treated pot $(20 \mathrm{~cm})$ while untreated seeds in inoculated control (respectively). (Graph A).

\section{Effect on Percent Seedling Mortality:-}

Percent seedling mortality was recovered in untreated seeds in uninoculated soil was $40 \%$, in coated seeds in inoculated soil was $6.25 \%$, in filtrate treated seeds in inoculated soil was $12.5 \%$ and untreated seeds in inoculated soil was $87 \%$.(Graph B)

\section{Effect on percent disease control:-}

Percent disease control was calculated to be $86.99 \%$ for antagonist filtrate treated seeds in infected soil and $93.62 \%$ for antagonist coated seeds in infected soil over untreated seeds in Fusarium infested soil taken as check (Graph C).

\section{Discussion:-}

In the present study, Trichoderma sp. was found to be very effective in the supression of mycelial growth of Fusarium oxysporum grown on PDA medium. The results obtained in the present study are in accordance with the findings of Jee and Kim (1999), Fernandez (1992) and Elad et.al. (1980). Hadar et.al. (1979) observed that, an isolate of Trichoderma sp. directly attacked the mycelia of Rhizoctonia solani when two fungi were grown together on a glucose plus mineral medium. In another study Jee and Kim (1987) observed several mycoparasitism mechanisms such as coiling, penetration, overgrowing and lysis on dual culture of water agar between antagonistic fungi Trichoderma harzianum, T. viride and F. oxysporum fsp. cucumeum. Elad et.al, recorded that an isolate of $T$. harzianum was capable of lysing mycelia of Sclerotium rolfsii and Rhizoctonia solani.

Trichoderma sp. was observed as one of the rapid growing fungus and covered most of the surrounding area of PDA plates. Elad et.al. (1980) also recorded same properties of mycelial growth of T. harzianum when it was grown with Sclerotium rolfsii. In their study $T$. harzianum grew better tha Sclerotium rolfsii and invaded its mycelia under growth conditions adverse to pathogens. According to Moon et.al (1988), the mode of mycoparasitism of $T$. harzianum appeared to be coiling around and its attachment on the host or penetration into the host hyphae or breaking septa of both the hyphae and the conidia. While studying the direct application of Trichoderma sp. on the infection of Fusarium sp. a soil borne pathogen of cucumber plants grown in pots, no plant infection was recorded due to its antagonistic properties. Elad et.al. (1980) reported that under green house conditions, incorporation of the wheat bran inoculum preparation of T. harzianum in pathogen infested soil, significantly reduced bean disease caused by Sclerotium rolfsii, Rhizoctonia solani or both. Fernandez (1992) reported that application of Trichoderma harzianum to soyabean residue resulted in a significant decrease in the incidence of some wheat, soyabean, black oat pathogens including Fusarium gramintarum and Fusarium sp. According to the study, T. harzianum was more effective in colonizing the substrate and in reducing the incidence of pathogen in wheat than in black oat. 
The plants appeared more healthier and robust than those of control. These findings are supported by Weindling, et. al, (1934) Cho et.al. (1989), Larena et.al. (2002). Manoranj itham et. al. (1999) reported increased. The germination, shoot length, root length, dry matter production and vigour index compared to control in $T$. viride treated seeds. Kharakrang et. al, (2002) reported significant increase in growth fresh and dry weight of potato plants grown in $T$. harzianum treated soil. Disease control practices, especially those based on potentially hazardous pesticides, biolgoical control measures are gaining support as a practical method for soil borne disease control. The idea to introduce antagonistic organisms to soil as control agents has long been considered. Therefore in our study, direct application of Trichoderma sp. .has proved effective in controlling the infection by Fusarium (soil borne pathogen) one of cucumber plants. Moreover their abundance coupled with their ability to produce some biochemicals such as enzymes, antibiotics or functional inhibitors to inhibit pathogen development and to promote plant growth by virtue of their growth stimulating effect can revolutionize agriculture.

\section{Acknowledgement}

Authors are thankful to the Center of Excellence Programme of UP state Government Letter No.: 1205/70-42013-46 (43) 2010 TC-11 for financial support.

\section{Reference:-}

1. Cho, C.T, Moon, B.J and Ha, S.Y. (1989). Biological control of Fusarium oxysporum fsp. cucumerinum causing cucumber wilt by Gliocladium virens and Trichoderma harzianum. Korean J. of Plant Pathology. 5:239-249.

2. Elad, Y. Chet, I and Katan, J. (1980). Trichoderma harzianum: A bio control agent effective against Sclerotium rofsii and Rhizoctonia solani. Phytopathology. 70: 119-121.

3. Fernandez, M.R. (1992). The effect of Trichoderma harzianum on fungal pathogens infested soyabean residue. Soil BioI. Biochem.24:1027-1029.

4. Freeman, S. Zveibil, A. Vintal, H and Maymon, M. (2002). Isolation of nonpathogenic mutants of Fusarium oxysporum f.sp. melonis for biological control of Fusarium wilt in cucurbits. : Phytopathology. 92:164-168.

5. Hadar, Y. Chet, I and Henis, Y. (1979). Biological control of Rhizoctonia solani damping off with wheat bran culture of Trichoderma harzianum. Phytopathology. 69:64-98.

6. Jee, H.J and Kim, H.K. (1987). Isolation, identification and antagonisms of rhizosphere antagonists to cucumber wilt pathogen, Fusaium oxysporum fsp. cucumerinum Owen. Korean J. Plant Pathology. 3:187-197.

7. Khurakrang, L. Kabitarani, A.Upadhyay, S and Upadhyay D.N.(2002). Disease control and growth promotion in tomato, potato and paddy by Trichoderma viride and T. harzianum. Indian J. Plan Pathology. 20(1 and 2) : 25-29.

8. Kim, W.G; Cho, W.D; and Jee, H.J. (1999). Occurence of sclerotic rot on cucurbitaceous vegetable crops in green houses. Korea. J. of Mycology. 27: 198-205.

9. Larena, I. Melgareja, P. and De Cal, V. (2002). Production, survival and evaluation of solid -substrate inocula of Penicillium oxalicum, a biocontrol agent against Fusarium wilt of tomato. Phytopathology. 92:863-86'9.

10. Manoranjitham, S.K. Prakasam. V. and Rajappan, K. (1999). Effect of antagonists on Pythium aphanidermatum (edson) Fitz and the growth of Chilli seedlings. J. Bioi. Control. 13: 101-106.

11. Moon, B.J. Chung, H.S and Cho, C.T. (1988). Studies on antagonism of Trichoderma sp. to Fusarium oxysporum .fr. fragariae Isolation, identification and antagonistic properties of Trichoderma species. Korean, J. Plant Pathology. 4:111-123.

12. Weindling, R. (1934). Studies on lethal principle effective in parasitic action of Trichoderma lignorum on Rhizoctonia solani and other soil fungi. Phytopathology. 24: 1153-1174. 